\title{
Enhanced Thermal and Electrical Properties of Polystyrene-Graphene Nanofibers via Electrospinning
}

\author{
Yan Li, ${ }^{1,2}$ Harshit Porwal, ${ }^{1,2}$ Zhaohui Huang, ${ }^{3}$ Han Zhang, ${ }^{1,2}$ \\ Emiliano Bilotti, ${ }^{1,2}$ and Ton Peijs ${ }^{1,2}$ \\ ${ }^{1}$ School of Engineering and Materials Science, Queen Mary University of London, London E1 4NS, UK \\ ${ }^{2}$ Nanoforce Technology Ltd., Joseph Priestley Building, Mile End Road, London E1 4NS, UK \\ ${ }^{3}$ School of Materials Science and Technology, China University of Geosciences, Beijing, China \\ Correspondence should be addressed to Emiliano Bilotti; e.bilotti@qmul.ac.uk and Ton Peijs; t.peijs@qmul.ac.uk
}

Received 20 July 2016; Accepted 18 September 2016

Academic Editor: Alessandro Pegoretti

Copyright (C) 2016 Yan Li et al. This is an open access article distributed under the Creative Commons Attribution License, which permits unrestricted use, distribution, and reproduction in any medium, provided the original work is properly cited.

Polystyrene- (PS-) graphene nanoplatelets (GNP) (0.1, 1, and $10 \mathrm{wt} . \%)$ nanofibers were successfully produced via electrospining of dimethyformamide- (DMF-) stabilized GNP and PS solutions. Morphological analysis of the composite nanofibers confirmed uniform fiber formation and good GNP dispersion/distribution within the PS matrix. The good physical properties of GNP produced by liquid exfoliation were transferred to the PS nanofibers. GNP modified PS nanofibers showed a 6-fold increase in the thermal conductivity and an increase of 7-8 orders of magnitude in electrical conductivity of the nanofibers at 10 wt.\% GNP loading.

\section{Introduction}

Electrospining can produce nanofibers, from a variety of precursor materials, by the application of electrostatic forces to a jetting polymer solution [1-5]. Adding nanofillers into electrospun polymer solution could improve the nanofibers properties for further applications, especially mechanically reinforced composites $[6,7]$, conductive membranes for fuel cell applications [8] and thin film batteries [9], due to the mats' high surface area to volume ratio, large porosity, good mechanical properties, and controllable size $[9,10]$. Electrospinning has used to produce nanofibers from a variety of natural/synthetic polymers, such as polyacrylonitrile, polyurethane, polycarbonate, polyvinyl alcohol (PVA), phenolic resin, and polystyrene. Graphene's superb properties (theoretical specific area of ca. $2630 \mathrm{~m}^{2} \cdot \mathrm{g}^{-1}$, thermal conductivity of ca. $5000 \mathrm{~W} \cdot \mathrm{m}^{-1} \cdot \mathrm{K}^{-1}$, intrinsic mobility of $2 \times$ $10^{5} \mathrm{~cm}^{2} \cdot \mathrm{s}^{-1} \cdot \mathrm{v}^{-1}$, high Young's modulus of ca. $1.0 \mathrm{TPa}$, and strength of $130 \mathrm{GPa}$ [11]) have the potential for replacing other commercial nanofillers like carbon nanotubes [12] as multifunctional filler in electrospun polymer fibers. GNP offers an alternative due to its physical and chemical properties, easy processability, and potential low cost [13]. Few studies have actually examined the possibility of using graphene derivatives as reinforcement in polymer nanofibers. Bao et al. [14] reported poly vinyl acetate-graphene oxide (GO) electrospun nanocomposites where GO was mainly used to improve the optical properties. Das et al. [1] reported electrospun PVA nanofibers loaded with functionalized graphene with increased thermal stability and crystallinity. Kim et al. reported silica/carbon nanofiber (CNF) composites prepared from a graphene/polyacrylonitrile (PAN) solution using electrospinning [2].

Electrospinning of polystyrene nanofiber has been reported before [15-18]. However, defects such as beads or necklace-like fibers were often concomitant with the electrospinning process, which adversely affects the reproducibility of the process and the homogeneity of the resultant nanofiber fabrics. In the present work, GNPs produced from liquid phase exfoliation with controlled size were used to prepare electrospun PS-GNP composite nanofibers. The critical electrospinning parameters which affect the morphology and properties of the PS-GNP composite nanofibers were optimized and thermal and electrical properties measured. 
TABLE 1: Composition of the electrospinning solutions.

\begin{tabular}{lcccccc}
\hline GNP wt.\% in PS & $\begin{array}{c}\text { PS } \\
(\mathrm{g})\end{array}$ & $\begin{array}{c}\text { DMF } \\
(\mathrm{g})\end{array}$ & $\begin{array}{c}\text { GNP } \\
(\mathrm{g})\end{array}$ & Solution A & Solution B & Solution for electrospinning \\
\hline 0 & 10 & 40 & 0 & PS (10 g) + DMF (40 g) & & A \\
0.1 wt.\% & 10 & 40 & 0.01 & PS (10 g) + DMF (30 g) & GNP (0.01 g) + DMF (10 g) & Mix A + B \\
1 wt.\% & 10 & 40 & 0.101 & PS (10 g) + DMF (30 g) & GNP (0.101 g) + DMF (10 g) & Mix A + B \\
10 wt.\% & 10 & 40 & 1.11 & PS (10 g) + DMF (30 g) & GNP (1.11 g) + DMF (10 g) & Mix A + B \\
\hline
\end{tabular}

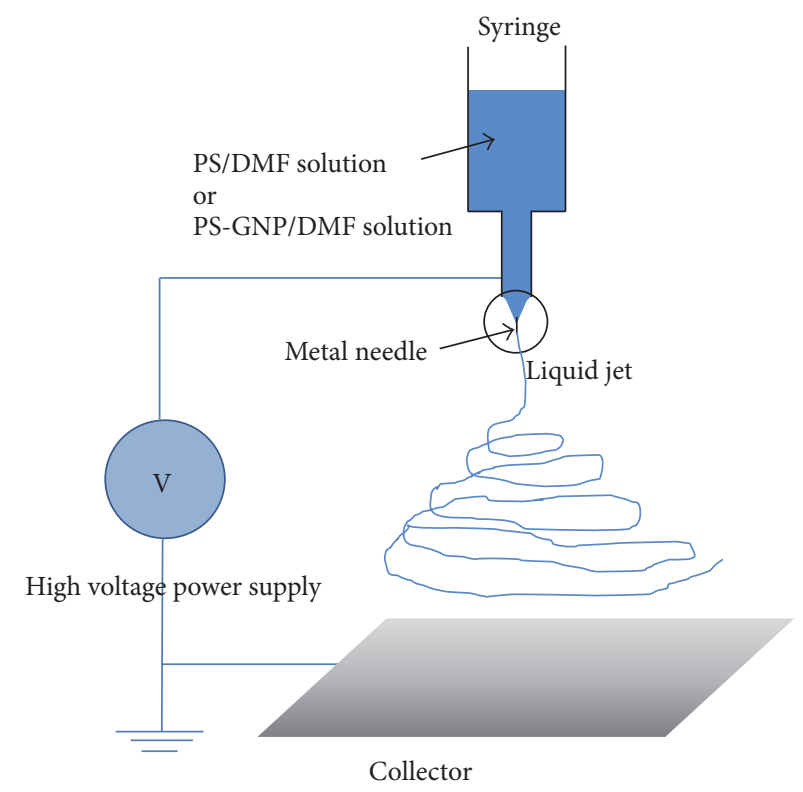

FIGURE 1: Schematic representation of electrospinning set-up.

\section{Experimental}

Natural graphite (NG) was purchased from Alfa Aesar (product number 43319). N-Methyl-2-pyrrolidone (NMP) $\left(\mathrm{C}_{5} \mathrm{H}_{9} \mathrm{NO}, M_{w}: 99.13 \mathrm{~g} / \mathrm{mol}\right)$; dimethyformamide (DMF) $\left(\mathrm{C}_{3} \mathrm{H}_{7} \mathrm{NO}, M_{w}: 73.09 \mathrm{~g} / \mathrm{mol}\right)$ solvents and polystyrene (product number $331651, M_{w}: 35,000 \mathrm{~g} / \mathrm{mol}$ ) were purchased from Sigma-Aldrich and used as received. Tetrabutylammonium bromide (TBAB) $\left(\mathrm{C}_{16} \mathrm{H}_{36} \mathrm{BrN}, M_{w}: 322.37 \mathrm{~g} / \mathrm{mol}\right)$ salt was purchased from Bio Basic Inc., which was used to improve the conductivity of the PS/DMF solution in order to improve spinnability.

2.1. GNP and PS-GNP/DMF Solutions. GNP was manufactured according to the method described in [19] via ultrasonication of natural graphite in NMP using an ultrasonic probe (Model GEX 750, $750 \mathrm{~W}, 20 \mathrm{kHz}$, Amplitude at 20\%, continuous power). The resultant dispersion was then centrifuged (CF) using a Hettich Mikro 22R centrifuge for $45 \mathrm{~min}$ at $500 \mathrm{rpm}$ to remove nonexfoliated graphite from the GNP suspension. The prepared GNP suspension was filtered and redispersed in DMF. It should be noted that NMP was used for exfoliation of GNP, while DMF was used for processing of nanofibers because of the lower boiling point. PS solutions $(20 \% \mathrm{w} / \mathrm{w})$ were prepared by dissolving PS in DMF with and without the addition of salt (tetrabutylammonium bromide
(TBAB), $0.02 \% \mathrm{w} / \mathrm{v})$. PS-GNP $(0.1,1$, and $10 \mathrm{wt} . \%)$ composite solutions were prepared by mixing PS/DMF solution and GNP/DMF dispersions (see Table 1). A reference sample was prepared by electrospinning PS/DMF solution without GNP.

2.2. Electrospinning. Electrospinning schematic set-up of this work is illustrated in Figure 1. PS/DMF and PS-GNP (0.1, 1 , and $10 \mathrm{wt} . \%) / \mathrm{DMF}$ solutions were placed in a syringe connected with a metal needle that was controlled by a syringe pump (KD Scientific, Model 780200) at a constant flow rate of $1.0 \mathrm{~mL} / \mathrm{hr}$, with an injection volume of $100 \mu \mathrm{L}$. A high voltage power supply (Gamma High Voltage Supply, Model ES 30-0.1 P) was used to generate a potential difference of $20 \mathrm{kV}$ between the needle tip and the collector (a static aluminium foil) grounded target placed $15 \mathrm{~cm}$ from the tip of the needle. All the experiments (Table 2) were carried out at $25^{\circ} \mathrm{C}$ and a relative humidity of ca. $40 \%$.

2.3. Characterizations. Scanning electron microscopy (SEM, FEI, Inspector-F) was conducted to assess the morphology of the graphite, exfoliated GNPs, and electrospun PS and PSGNP nanofibers. Transmission Electron Microscopy (TEM, JOEL JEM-2010) was utilized to see the morphology and the dispersion of GNP in the PS-GNP nanofibers. Raman spectroscopy (Nicolet Almega XR) was utilized to characterize natural graphite, exfoliated GNP, and nanofiber. Low 
TABLE 2: GNP concentrations in PS and parameters of electrospinning process.

\begin{tabular}{lccc}
\hline GNP in PS (wt.\%) & Voltage $(\mathrm{kV})$ & Tip-target distance $(\mathrm{cm})$ & Flow rate $(\mathrm{mL} / \mathrm{hr})$ \\
\hline 0 & $10 / 15 / 20$ & $10 / 15 / 20 / 30$ & $0.2 / 0.5 / 1.0$ \\
\hline \multicolumn{4}{c}{ Optimized parameters } \\
\hline $0.1 / 1.0 / 10$ & 20 & 15 & 1.0 \\
\hline
\end{tabular}

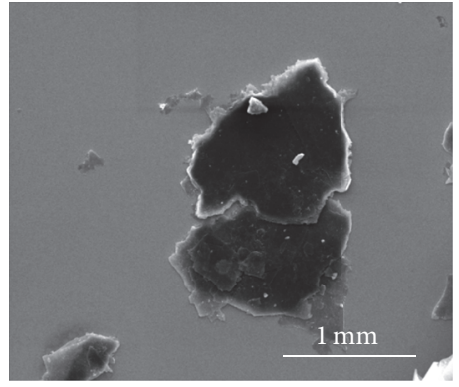

(a)

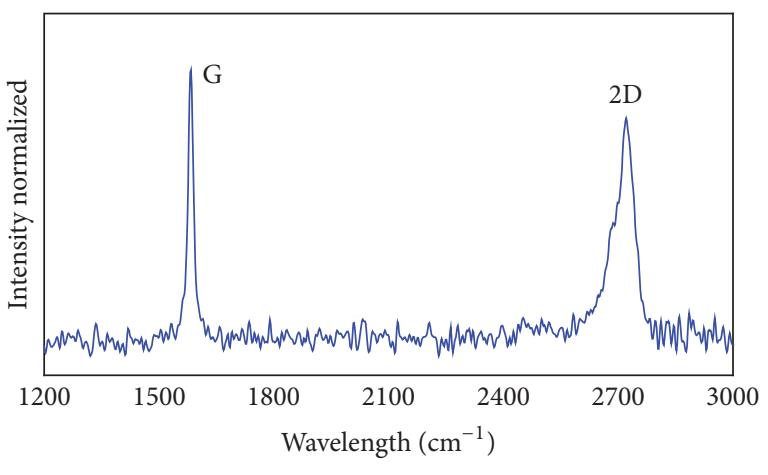

- Natural graphite

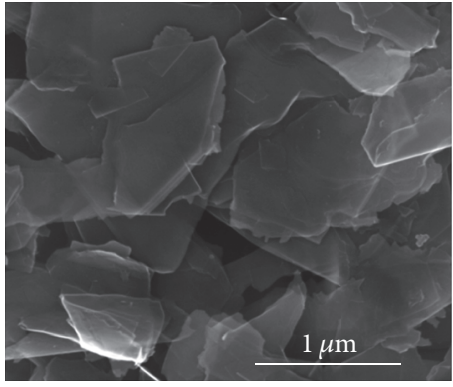

(b)

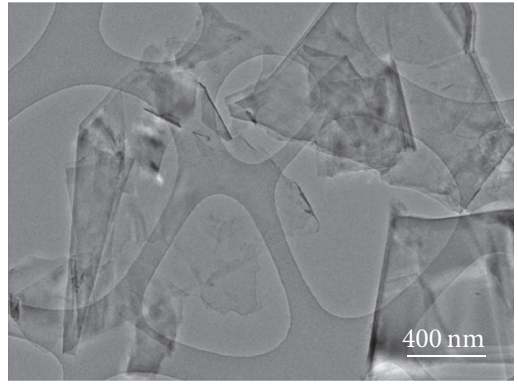

(c)

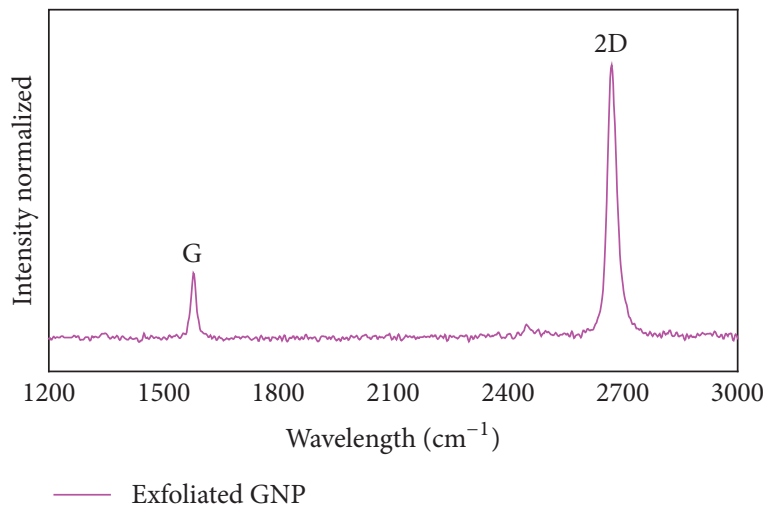

(d)

FIGURE 2: Showing SEM images of (a) graphite, (b) GNP, (c) TEM image of exfoliated GNP, and (d) Raman spectra of graphite and GNP.

laser energy was employed for nanofibers to avoid damage. Thermal diffusivity $(\alpha)$ of PS-GNP was measured by the Netzsch LFA 457 Laser between 20 and $50^{\circ} \mathrm{C}$ and thermal conductivity $(\lambda)$ was calculated using the following formula:

$$
\lambda(T)=\alpha(T) * C_{P}(T) * \rho(T),
$$

where density $(\rho)$ was calculated using rule of mixture $\rho=$ $m_{\text {total }} /\left(m_{\text {filler }} / \rho_{\text {filler }}+m_{\text {polymer }} / \rho_{\text {polymer }}\right)[20]$ and specific heat $C_{P}$ was measured using a Perkin Elmer differential scanning calorimeter [21]. The electrical conductivity of PS-GNP fiber mats $(10 \mathrm{~mm} \times 50 \mathrm{~mm} \times 0.2 \mathrm{~mm})$ was measured by two-point probe method using a picoammeter (Keithley 6485) and a DC voltage source (Agilent 6614C).

\section{Results and Discussion}

Length $(l)$, width $(w)$, and thickness $(t)$ of the natural graphite flakes were approximately 800,600 , and $26 \mu \mathrm{m}$, respectively (Figure 2(a)). After exfoliation, the average length and width of the exfoliated GNP were $1.1 \pm 0.4 \mu \mathrm{m}$ (Figure 2(b)), while the thickness was $\sim 2 \mathrm{~nm}$ (aspect ratio $\sim 500$ ). The edges of graphene sheets (Figure 2(c)) indicated that singlelayer graphene and few-layer graphene were obtained after liquid phase exfoliation. Raman spectra (Figure 2(d)) confirmed the peaks of graphite and exfoliated graphene. Please refer to Supplementary Material available online at http://dx.doi.org/10.1155/2016/4624976 for Raman data on nanofibers, showing typical spectra with $\mathrm{D}, \mathrm{G}$, and $2 \mathrm{D}$ peaks.

In order to obtain consistent, bead-free nanofibers, electrospinning parameters and solution formulation were optimized. A series of preliminary experiments were performed to study the effect of flow rate, applied voltage, and tip-target distance on fiber formation (Table 2). Finally, bead-free PSGNP composite fibers were obtained after achieving optimal conditions for the electrospinning process. Bead formation was decreased with increasing flow rate at a fixed voltage of $20 \mathrm{kV}$. A flow rate of $1.0 \mathrm{~mL} / \mathrm{hr}$ resulted in good quality nanofibers free of beads defects. In the case of electrospun PS fibers (20 wt.\% PS in DMF) without TBAB (Figures 3(a1), $3(\mathrm{a} 2)$, and 3(a3)), the average diameter of the fibers was slightly larger because of the relatively higher PS concentration and hence viscosity of the spinning solution but also as a consequence of lower ionic conductivity. The effects of the 


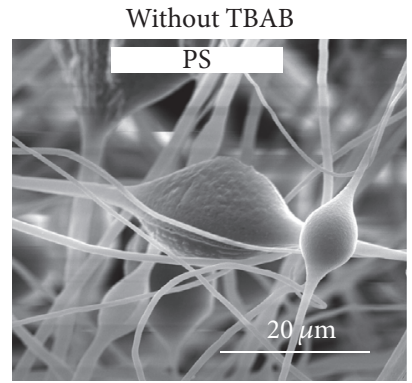

(a1)

With TBAB

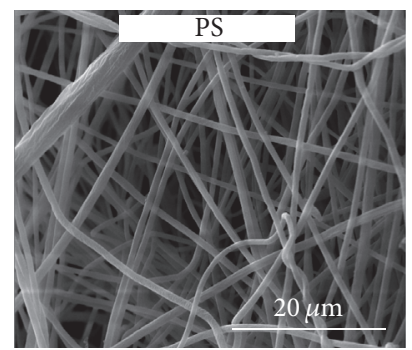

(b1)

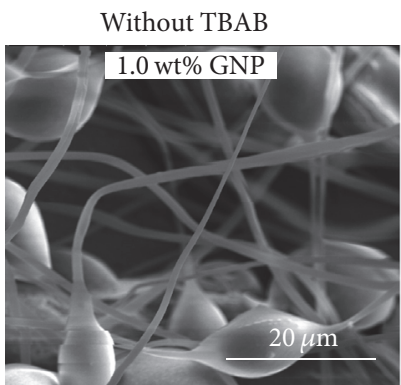

(a2)

With TBAB

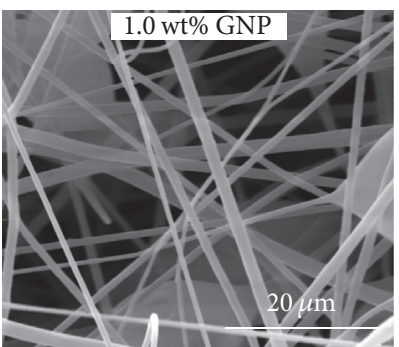

(b2)

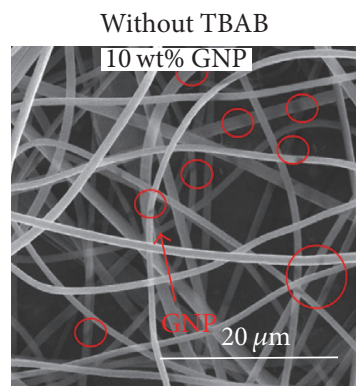

(a3)

With TBAB

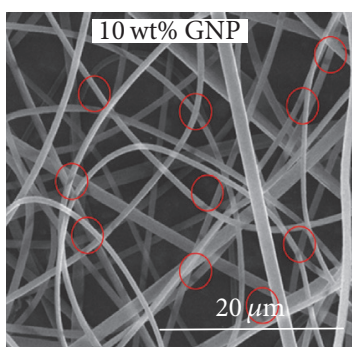

(b3)

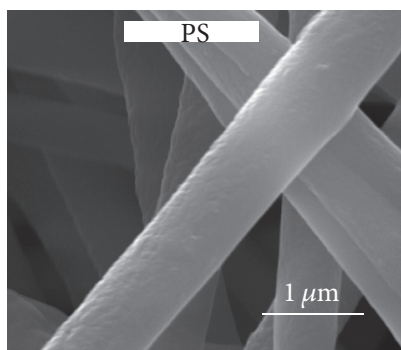

(c1)

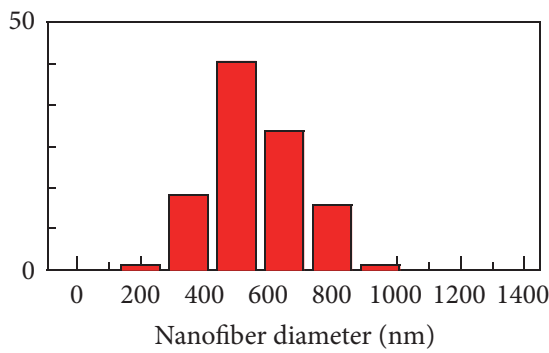

PS-GNP (10 wt $\%)$

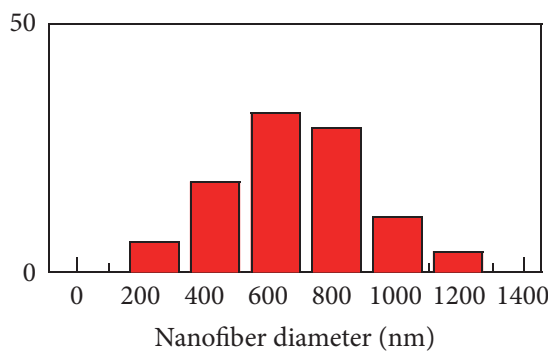

PS-GNP (0.1 wt $\%)$

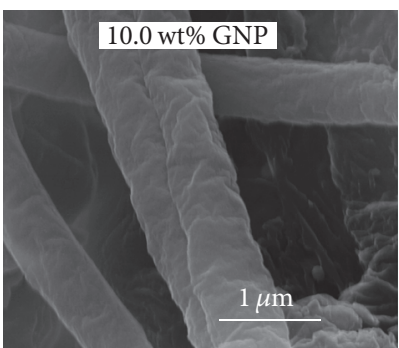

(c2)

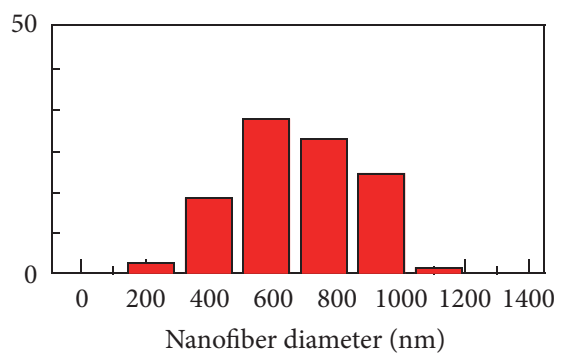

PS-GNP (1.0 wt $\%)$

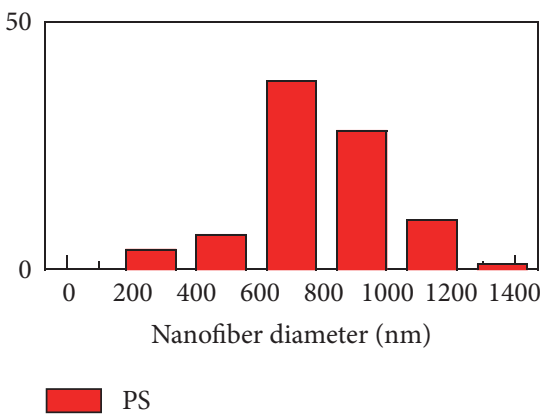

(c3)

FIgURE 3: SEM images of nanofibers without and with TBAB and statistics of the diameters of nanofibers with TBAB. 


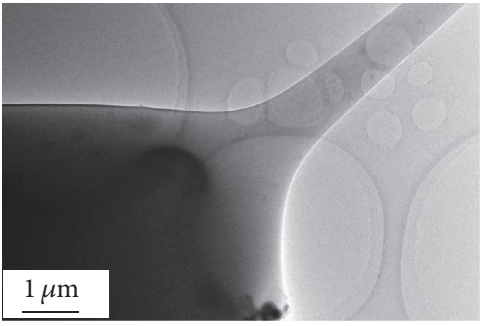

(a1)

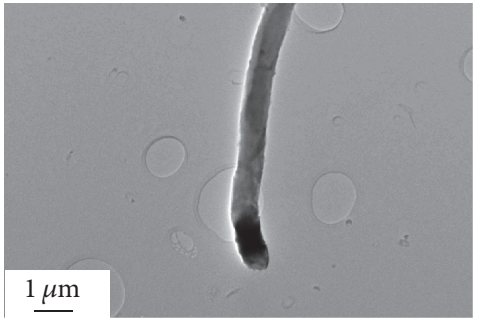

(b1)

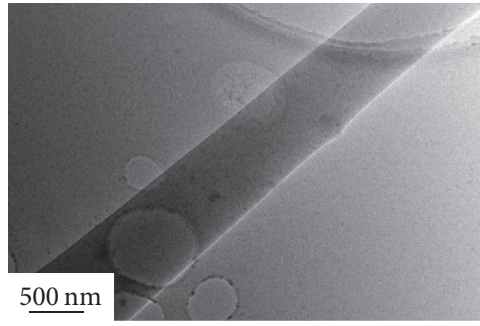

(a2)

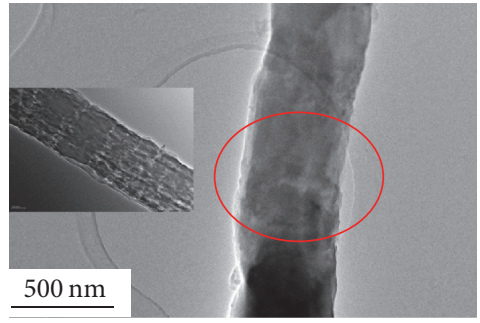

(b2)

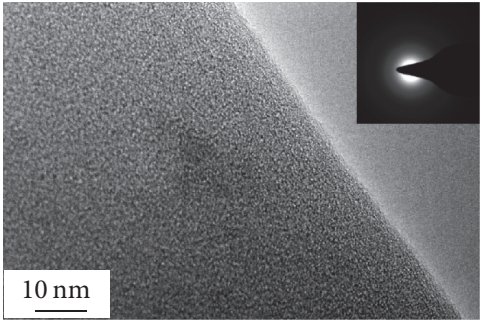

(a3)

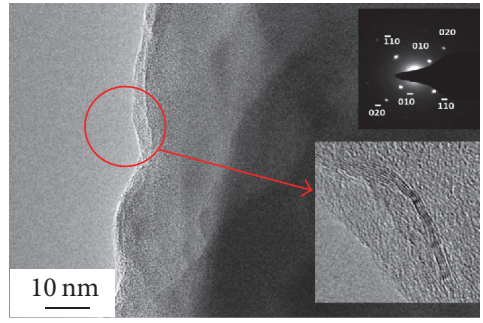

(b3)

FIGURE 4: TEM images of neat PS ((a1), (a2), and (a3)) and PS-GNP (10 wt.\%) nanofibers ((b1), (b2), and (b3)).

viscosity and the ionic conductivity of the spinning solution have been extensively reported in the literature. In terms of viscosity, it has been observed that there is an optimal spinning window, usually between $\sim 1$ and 200 poises [22]. Beaded PS fiber structures have been observed for lower viscosities, while bead-free PS fibers have been observed for higher viscosities [23]. For even more extreme (low or high) viscosities, spinning of continuous fibers is completely inhibited $[16,24,25]$.

The increase in the solution ionic conductivity usually results in improvement in electrospinning production with bead-free, uniform, and thinner fibers, caused effectively by a stronger elongation force and higher draw-down due to the increased charge density of the ejected jet $[18,26$, 27]. Conductivity of solution mainly depends on polymer type, solvent used, and the availability of ionisable additives like salts. Low conductivity of the solution will result in elongation of the jet insufficient to produce uniform fiber under electrostatic forces; in this case, beads may also be observed. However, too high conductivities are extremely unstable in presence of strong electric fields resulting in a dramatic bending instability as well as a broad diameter distribution [28]. Slight changes in solution conductivity can result in significant morphological variations in electrospun fibers [27] as also noticed in our study (Figures 3(b1), 3(b2), and $3(\mathrm{~b} 3)$ ).

The addition of TBAB to the PS solution significantly improved the electrospinning process, changing the morphology from bead on-string structure to continuous and homogeneous fiber structure and leading to a smaller fiber diameter and narrower fiber diameter distribution [26, 27]. This is in agreement with previous published papers [27, 29, 30]. Uyar and Besenbacher [27] produced uniform PS fibers from DMF solutions with the addition of TBAB salt and revealed that bead-free fibers were obtained when the conductivity of PS solution is $150-180 \mu \mathrm{S} / \mathrm{cm}$. Nitanan et al. [26] revealed that an excessively high amount of TBAB $(0.5$ and $1.0 \% \mathrm{w} / \mathrm{v}$ ) could result in the clogging of PS solution at capillary tip.

PS-GNP (10 wt.\%) without TBAB also resulted in good quality nanofiber without bead formation (Figure 3(a3)). The diameter of the nanofibers decreased with addition of GNP (Figure 3(c); please refer to Supplementary Material for more SEM images about nanofibers). The average diameters of PS and PS-GNP nanofibers (0.1, 1, and 10 wt.\%) with TBAB was $680 \pm 220,620 \pm 190,580 \pm 180$, and $500 \pm 150 \mathrm{~nm}$, respectively. The textural morphology of the GNP-loaded fibers was different from that of the neat PS fibers (i.e., rougher and uneven surface) (Figures $3(\mathrm{cl})$ and $3(\mathrm{c} 2)$ ). The addition of an appropriate amount of GNPs can be beneficial to shifting the electrical conductivity and the viscosity of the spinning solution toward the respective optimal windows (i.e., optimal conductivity of PS solution $\leq 550 \mu \mathrm{S} / \mathrm{cm}$ [26]) and viscosity between $\sim 1$ to 200 poises [22].

Also, TEM analysis showed similar results. The diameter of the PS/GNP nanofibers was smaller compared to the neat PS nanofibers (Figure 4). The surface roughness of the nanofibers increased with addition of GNP, although GNP was well dispersed and distributed in the PS matrix without aggregation. The surface morphology of the nanofibers changed from relatively smooth to mostly rough. Some nanofiber surfaces showed graphene layers (inset in Figure 4(b3)).

It is noted that the total amount of the solvent used throughout the present work was the same, regardless of the addition of GNPs. With the addition of GNPs, the effective concentration of PS is slightly reduced and the conductivity of PS-GNP/DMF increased [26]. This might explain the reduction of the fiber diameter with addition of GNP. This is in agreement with a previous publication [31].

Once the electrospinning process has been optimized, the effect of GNP in the thermal and electrical conductivity of PS nanofibers is studied. Figure 5(a) compares the thermal conductivity of PS-GNP nanofibers with other electrospun mats 

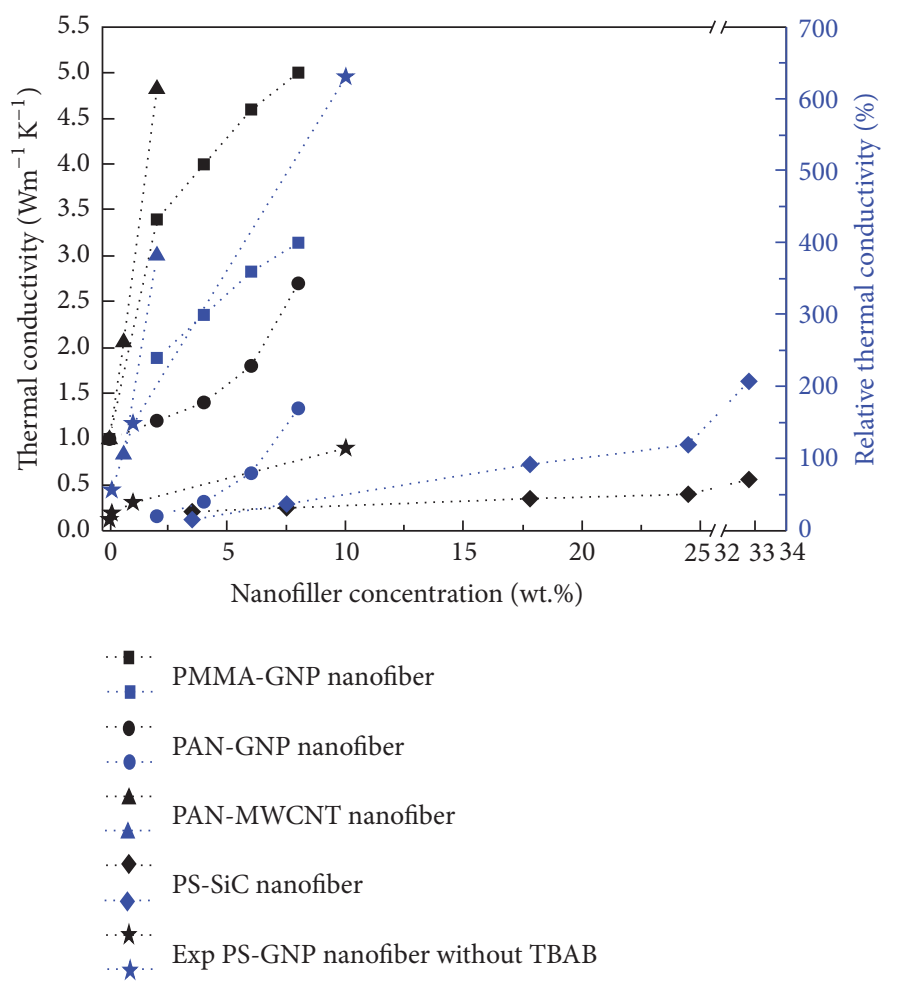

(a)

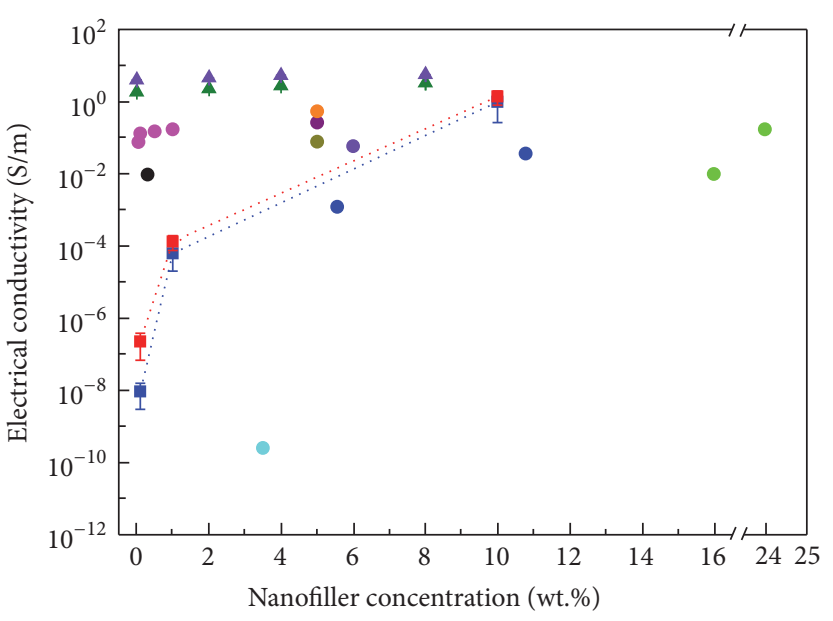

- SIBS-SWCNT, Liu et al.

PMMA-SWCNT, Natarajan et al. PVDF/(MWCNT-PANi), Sarvi et al.

PVA-MWCNT-COOH, Ding et al.

PAN-MWCNTs, Mohammadpour and Rafizadeh

PVA-MWCNT, Agrawal et al.

PET-SWCNT, Mazinani et al.

PET-DWCNT, Mazinani et al.

PET-MWCNT, Mazinani et al.

PMMA-GNP, Khan et al.

PAN-GNP, Khan et al.

.. Our exp, PS-GNP $(0.1,1,10 \mathrm{wt} . \%)$ without TBAB

.. Our exp, PS-GNP $(0.1,1,10$ wt.\%) with TBAB

(b)

FIGURE 5: Comparison of (a) thermal and (b) electrical conductivities of electrospun PS-GNP nanofibers with other electrospun mats containing carbonaceous fillers and other similar systems from literature.

containing carbonaceous fillers and other similar systems [32-34]. Thermal conductivity substantially increased upon the addition of GNP, up to a $630 \%$ increase corresponding to 10 wt.\% GNPs loading, in line with best results published in the scientific literature (Figure 5(a)).

Figure 5(b) compares the electrical conductivity values of PS-GNP nanofibers with other electrospun mats containing carbonaceous fillers [31,34-42]. The electrical conductivity of PS/GNP nanofibers increased suddenly corresponding to a GNP content below $1 \mathrm{wt} . \%$ reaching $1.4 \pm 0.6 \mathrm{~S} / \mathrm{m}$ for $10 \mathrm{wt} . \%$ GNP loading. This is an electrical conductivity of 7-8 orders of magnitude higher than pure PS nanofiber mats.

GNP has proven to be an excellent choice as multifunctional nanofiller, showing great promise in improving both electrical and thermal properties. Hence, the produced ultrafine GNP nanofibers mats could be promising materials for applications in electrodes, conductive wires, and smart fabrics.

\section{Conclusions}

GNPs were produced using liquid phase exfoliation method and PS-GNP composite nanofibers (0.1, 1, and $10.0 \mathrm{wt} . \%)$ were produced via electrospinning of DMF solutions. After optimization of processing parameters, GNP was successfully and homogeneously incorporated within the PS nanofibers.
It was found that the addition of GNP leads to a decrease in fiber diameter and increased surface roughness of the nanofibers. Significant improvements in both thermal (6fold increase) and electrical conductivities (7-8 orders of magnitude) were achieved with the incorporation of up to 10 wt.\% GNP.

\section{Competing Interests}

The authors declare that there are no competing interests regarding the publication of this paper.

\section{Acknowledgments}

This research has received funding from Nanosynth Project which is funded by Innovate UK through the Technology Inspired Innovation-NANO Competition (Project no. 101257) and also received funding from Polygraph Project from the European Union's Seventh Framework Programme (Project no. 604143). Yan Li would like to acknowledge financial support from the China Scholarship Council (CSC).

\section{References}

[1] S. Das, A. S. Wajid, S. K. Bhattacharia, M. D. Wilting, I. V. Rivero, and M. J. Green, "Electrospinning of polymer nanofibers loaded with noncovalently functionalized graphene," 
Journal of Applied Polymer Science, vol. 128, no. 6, pp. 40404046, 2013.

[2] S. Y. Kim, B.-H. Kim, K. S. Yang, and K.-Y. Kim, “The formation of silica nanoparticles on the polyacrylonitrile-based carbon nanofibers by graphene via electrospinning," Materials Letters, vol. 71, pp. 74-77, 2012.

[3] J. Yao, C. Bastiaansen, and T. Peijs, "High strength and high modulus electrospun nanofibers," Fibers, vol. 2, no. 2, pp. 158186, 2014.

[4] M. Kancheva, A. Toncheva, N. Manolova, and I. Rashkov, "Enhancing the mechanical properties of electrospun polyester mats by heat treatment," Express Polymer Letters, vol. 9, no. 1, pp. 49-65, 2015.

[5] T. C. Mokhena, V. Jacobs, and A. S. Luyt, "A review on electrospun bio-based polymers for water treatment," Express Polymer Letters, vol. 9, no. 10, pp. 839-880, 2015.

[6] T.-E. Chang, A. Kisliuk, S. M. Rhodes, W. J. Brittain, and A. P. Sokolov, "Conductivity and mechanical properties of welldispersed single-wall carbon nanotube/polystyrene composite," Polymer, vol. 47, no. 22, pp. 7740-7746, 2006.

[7] W. Wang, P. Ciselli, E. Kuznetsov, T. Peijs, and A. H. Barber, "Effective reinforcement in carbon nanotube-polymer composites," Philosophical Transactions of the Royal Society A: Mathematical, Physical and Engineering Sciences, vol. 366, no. 1870, pp. 1613-1626, 2008.

[8] D. S. Kim, H. B. Park, J. W. Rhim, and Y. M. Lee, "Preparation and characterization of crosslinked $\mathrm{PVA} / \mathrm{SiO}_{2}$ hybrid membranes containing sulfonic acid groups for direct methanol fuel cell applications," Journal of Membrane Science, vol. 240, no. 1-2, pp. 37-48, 2004.

[9] I. S. Chronakis, "Novel nanocomposites and nanoceramics based on polymer nanofibers using electrospinning process-a review," Journal of Materials Processing Technology, vol. 167, no. 2-3, pp. 283-293, 2005.

[10] M. Obaid, G. M. K. Tolba, M. Motlak et al., "Effective polysulfone-amorphous $\mathrm{SiO}_{2} \mathrm{NPs}$ electrospun nanofiber membrane for high flux oil/water separation," Chemical Engineering Journal, vol. 279, pp. 631-638, 2015.

[11] M. J. Allen, V. C. Tung, and R. B. Kaner, "Honeycomb carbon: a review of graphene," Chemical Reviews, vol. 110, no. 1, pp. 132$145,2010$.

[12] Y. Dror, W. Salalha, R. L. Khalfin, Y. Cohen, A. L. Yarin, and E. Zussman, "Carbon nanotubes embedded in oriented polymer nanofibers by electrospinning," Langmuir, vol. 19, no. 17, pp. 7012-7020, 2003.

[13] K. R. Paton, E. Varrla, C. Backes et al., "Scalable production of large quantities of defect-free few-layer graphene by shear exfoliation in liquids," Nature Materials, vol. 13, no. 6, pp. 624630, 2014.

[14] Q. Bao, H. Zhang, Y. Wang et al., "Atomic-layer graphene as a saturable absorber for ultrafast pulsed lasers," Advanced Functional Materials, vol. 19, no. 19, pp. 3077-3083, 2009.

[15] R. Sen, B. Zhao, D. Perea et al., "Preparation of single-walled carbon nanotube reinforced polystyrene and polyurethane nanofibers and membranes by electrospinning," Nano Letters, vol. 4, no. 3, pp. 459-464, 2004.

[16] C. L. Casper, J. S. Stephens, N. G. Tassi, D. B. Chase, and J. F. Rabolt, "Controlling surface morphology of electrospun polystyrene fibers: effect of humidity and molecular weight in the electrospinning process," Macromolecules, vol. 37, no. 2, pp. 573-578, 2004.
[17] L. Wannatong, A. Sirivat, and P. Supaphol, "Effects of solvents on electrospun polymeric fibers: preliminary study on polystyrene," Polymer International, vol. 53, no. 11, pp. 1851-1859, 2004.

[18] T. Lin, H. Wang, H. Wang, and X. Wang, "The charge effect of cationic surfactants on the elimination of fibre beads in the electrospinning of polystyrene," Nanotechnology, vol. 15, no. 9, pp. 1375-1381, 2004.

[19] U. Khan, H. Porwal, A. Óneill, K. Nawaz, P. May, and J. N. Coleman, "Solvent-exfoliated graphene at extremely high concentration," Langmuir, vol. 27, no. 15, pp. 9077-9082, 2011.

[20] C. P. Wong and R. S. Bollampally, “Thermal conductivity, elastic modulus, and coefficient of thermal expansion of polymer composites filled with ceramic particles for electronic packaging," Journal of Applied Polymer Science, vol. 74, no. 14, pp. 33963403, 1999.

[21] J. Khaliq, Q. Jiang, J. Yang, K. Simpson, H. Yan, and M. J. Reece, "Utilizing the phonon glass electron crystal concept to improve the thermoelectric properties of combined Yb-stuffed and Tesubstituted CoSb 3," Scripta Materialia, vol. 72-73, pp. 63-66, 2014.

[22] J. M. Deitzel, J. Kleinmeyer, D. Harris, and N. C. Beck Tan, "The effect of processing variables on the morphology of electrospun nanofibers and textiles," Polymer, vol. 42, no. 1, pp. 261-272, 2001.

[23] I. Hayati, A. I. Bailey, and T. F. Tadros, "Investigations into the mechanisms of electrohydrodynamic spraying of liquids. I. Effect of electric field and the environment on pendant drops and factors affecting the formation of stable jets and atomization," Journal of Colloid and Interface Science, vol. 117, no. 1, pp. 205-221, 1987.

[24] S. L. Shenoy, W. D. Bates, and G. Wnek, "Correlations between electrospinnability and physical gelation," Polymer, vol. 46, no. 21, pp. 8990-9004, 2005.

[25] T. Jarusuwannapoom, W. Hongrojjanawiwat, S. Jitjaicham et al., "Effect of solvents on electro-spinnability of polystyrene solutions and morphological appearance of resulting electrospun polystyrene fibers," European Polymer Journal, vol. 41, no. 3, pp. 409-421, 2005.

[26] T. Nitanan, P. Opanasopit, P. Akkaramongkolporn, T. Rojanarata, T. Ngawhirunpat, and P. Supaphol, "Effects of processing parameters on morphology of electrospun polystyrene nanofibers," Korean Journal of Chemical Engineering, vol. 29, no. 2, pp. 173-181, 2012.

[27] T. Uyar and F. Besenbacher, "Electrospinning of uniform polystyrene fibers: the effect of solvent conductivity," Polymer, vol. 49, no. 24, pp. 5336-5343, 2008.

[28] H. Fong, I. Chun, and D. H. Reneker, "Beaded nanofibers formed during electrospinning," Polymer, vol. 40, no. 16, pp. 4585-4592, 1999.

[29] J. Zheng, A. He, J. Li, J. Xu, and C. C. Han, "Studies on the controlled morphology and wettability of polystyrene surfaces by electrospinning or electrospraying," Polymer, vol. 47, no. 20, pp. 7095-7102, 2006.

[30] K. Lin, K.-N. Chua, G. T. Christopherson, S. Lim, and H.-Q. Mao, "Reducing electrospun nanofiber diameter and variability using cationic amphiphiles," Polymer, vol. 48, no. 21, pp. 63846394, 2007.

[31] X. Wu, S. Mahalingam, A. Amir et al., "Novel preparation, microstructure, and properties of polyacrylonitrile-based carbon nanofiber-graphene nanoplatelet materials," ACS Omega, vol. 1, no. 2, pp. 202-211, 2016. 
[32] Q. Dong, C. Lu, K. Tulugan et al., “Thermal conductivity of diamond packed electrospun pan-based carbon fibers incorporated with multi wall carbon nanotubes," Journal of Nanoscience and Nanotechnology, vol. 16, no. 2, pp. 1843-1847, 2016.

[33] W. S. Khan, R. Asmatulu, I. Ahmed, and T. S. Ravigururajan, "Thermal conductivities of electrospun PAN and PVP nanocomposite fibers incorporated with MWCNTs and NiZn ferrite nanoparticles," International Journal of Thermal Sciences, vol. 71, pp. 74-79, 2013.

[34] W. S. Khan, R. Asmatulu, V. Rodriguez, and M. Ceylan, "Enhancing thermal and ionic conductivities of electrospun PAN and PMMA nanofibers by graphene nanoflake additions for battery-separator applications," International Journal of Energy Research, vol. 38, no. 15, pp. 2044-2051, 2014.

[35] Y. Liu, K. J. Gilmore, J. Chen, V. Misoska, and G. G. Wallace, "Bio-nanowebs based on poly(styrene- $\beta$-isobutylene- $\beta$ styrene) (SIBS) containing single-wall carbon nanotubes," Chemistry of Materials, vol. 19, no. 11, pp. 2721-2723, 2007.

[36] B. Sundaray, V. J. Babu, V. Subramanian, and T. Natarajan, "Preparation and characterization of electrospun fibers of poly (methyl methacrylate)-single walled carbon nanotube nanocomposites," Journal of Engineered Fibers and Fabrics, vol. 3, no. 4, pp. 39-45, 2008.

[37] Z. Ding, Y. Zhu, C. Branford-White et al., "Self-assembled transparent conductive composite films of carboxylated multi-walled carbon nanotubes/poly(vinyl alcohol) electrospun nanofiber mats," Materials Letters, vol. 128, pp. 310-313, 2014.

[38] A. Sarvi, A. B. Silva, R. E. Bretas, and U. Sundararaj, "A new approach for conductive network formation in electrospun poly(vinylidene fluoride) nanofibers," Polymer International, vol. 64, no. 9, pp. 1262-1267, 2015.

[39] M. Yanilmaz and A. S. Sarac, "A review: effect of conductive polymers on the conductivities of electrospun mats," Textile Research Journal, vol. 84, no. 12, pp. 1325-1342, 2014.

[40] R. Mohammadpour and M. Rafizadeh, "Preparation, morphology and conductivity of polyacrylonitrile/multi-wall carbon nanotubes composite nanofibers," Iranian Polymer Journal (English Edition), vol. 23, no. 9, pp. 731-743, 2014.

[41] S. L. Agrawal, N. Rai, T. S. Natarajan, and N. Chand, "Electrical characterization of PVA-based nanocomposite electrolyte nanofibre mats doped with a multiwalled carbon nanotube," Ionics, vol. 19, no. 1, pp. 145-154, 2013.

[42] S. Mazinani, A. Ajji, and C. Dubois, "Fundamental study of crystallization, orientation, and electrical conductivity of electrospun PET/carbon nanotube nanofibers," Journal of Polymer Science, Part B: Polymer Physics, vol. 48, no. 19, pp. 2052-2064, 2010. 

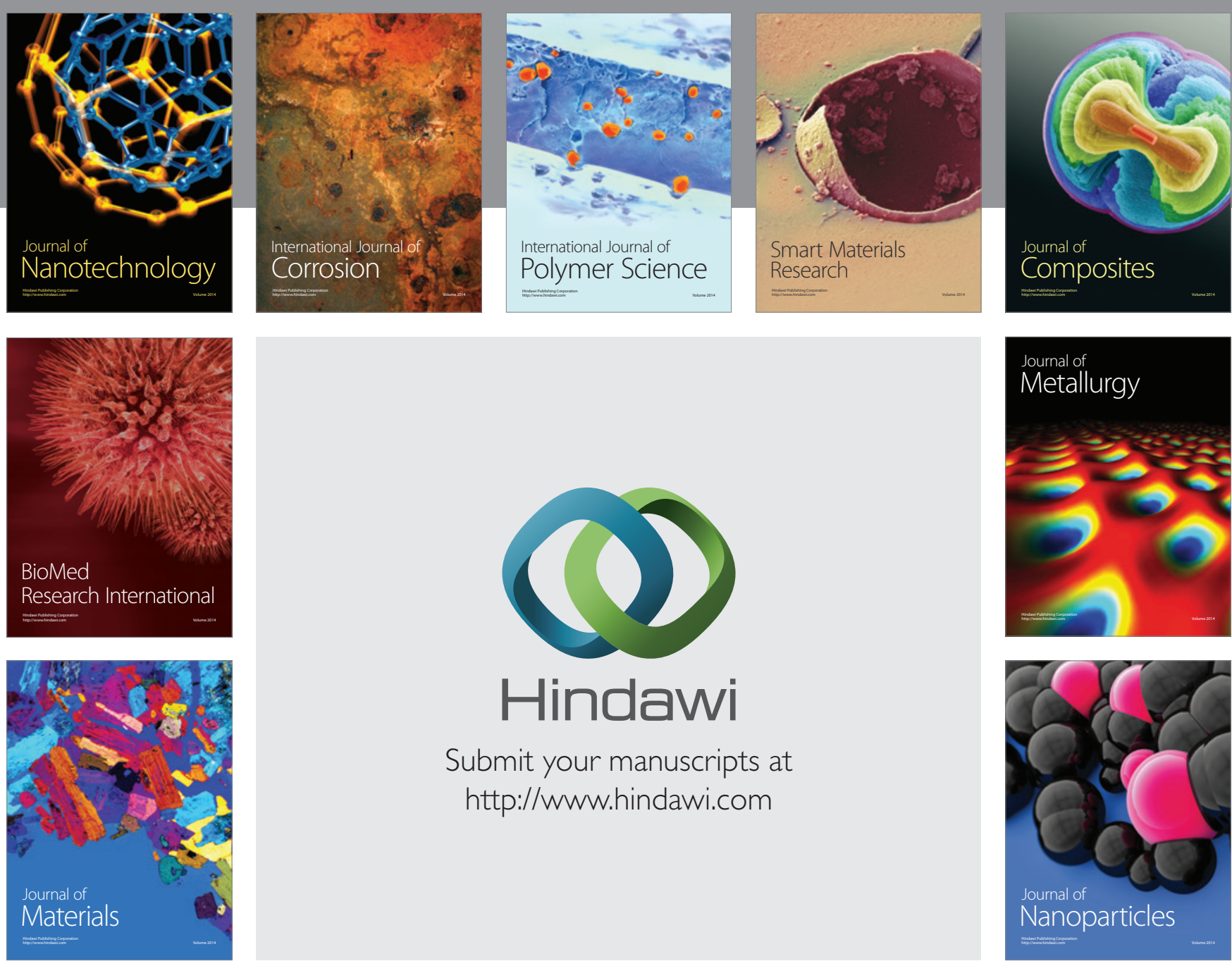

\section{Hindawi}

Submit your manuscripts at

http://www.hindawi.com

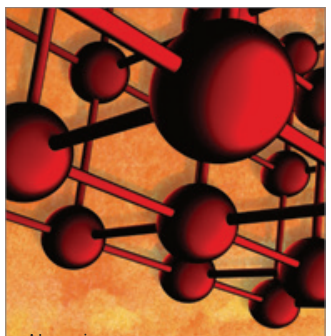

Materials Science and Engineering
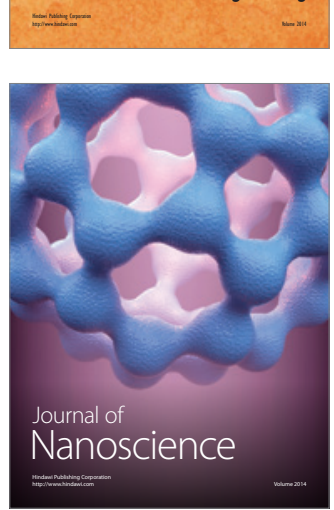
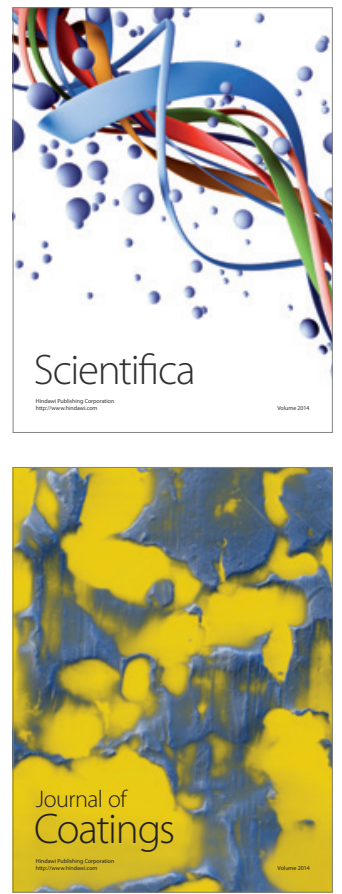
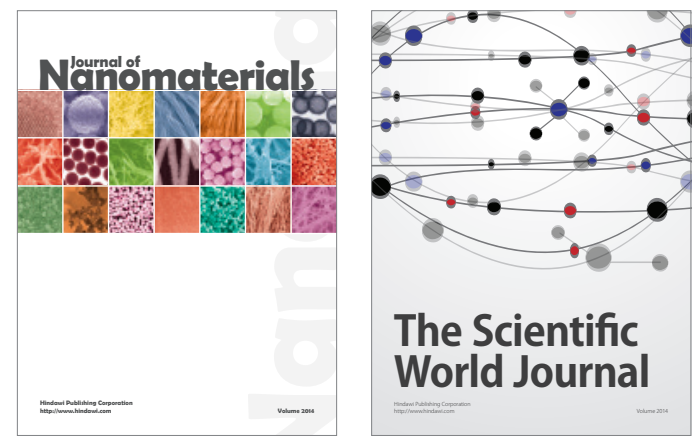

The Scientific World Journal
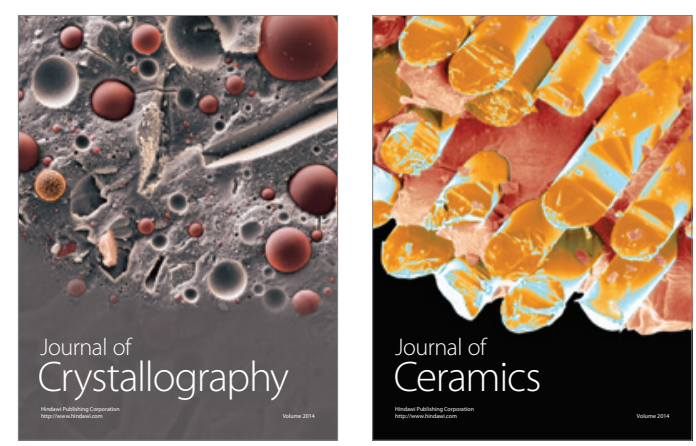
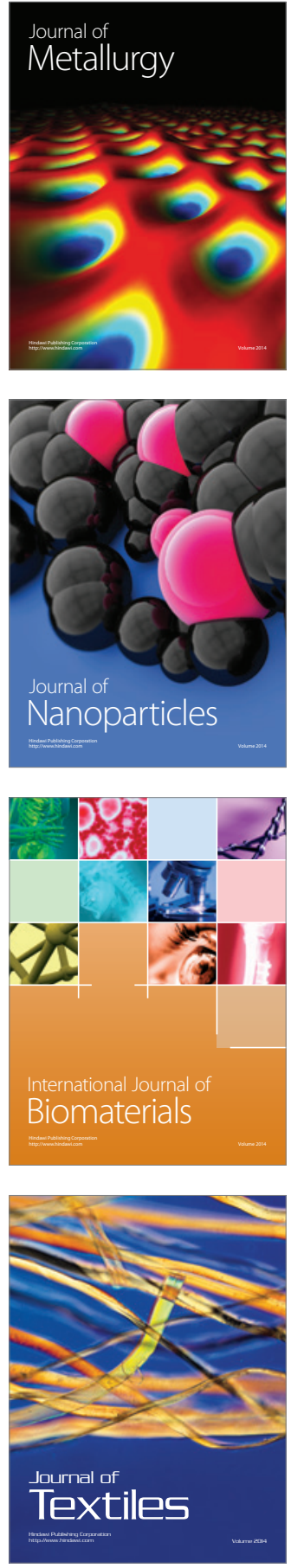